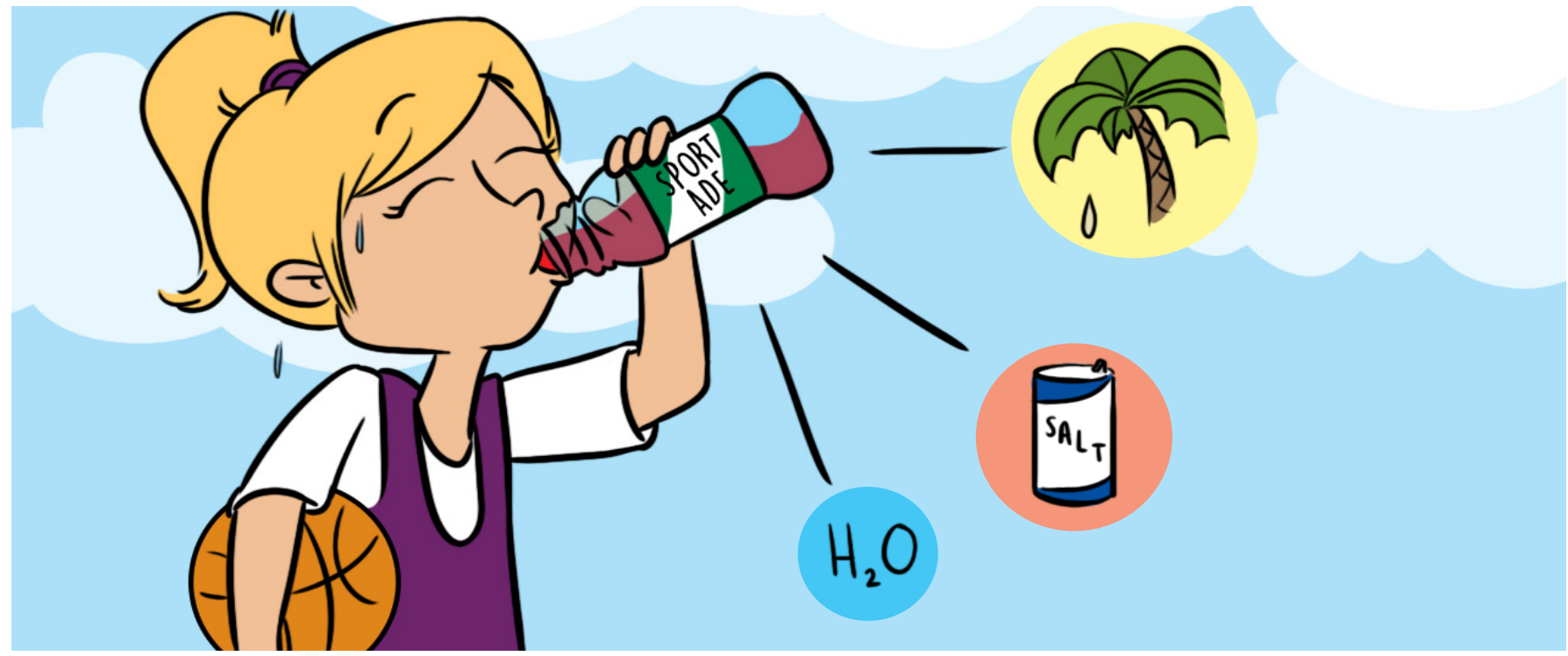

\title{
EMULSIONS CAN REPLACE ARTIFICIAL DYES
}

\section{IN BEVERAGES}

\section{Graziele G. Bovi1 ${ }^{12 *}$, Samantha C. Pinho ${ }^{1}$}

${ }^{1}$ Laboratory of Encapsulation and Functional Foods, Department of Food Engineering (ZEA), University of São Paulo (USP), São Paulo, Brazil, 'Laboratory of Packaging and Storage Systems, Department of Horticultural Engineering, Leibniz Institute for Agricultural Engineering and Bioeconomy (ATB), Potsdam, Germany

\section{REVIEWED BY:}

ALAA

AGE: 10
Have you ever asked yourself where the color of your processed food comes from? Do candies or sports drinks have their colors naturally? Well, in most cases, no. A food dye is added in order to make food more attractive for consumers. For that reason, the food industry makes use of dyes. Food dyes can be artificial or natural. As more and more people choose to buy and eat natural foods, the food industry is trying to use natural colorings instead of commonly used artificial additives. This article will describe the possibility of producing natural food dyes by a process called emulsification. But, what is emulsification? Simply, it is a process that enables water and oil to mix with each other. This article will describe how emulsification can be used to produce an emulsion with a very nutritious oil, called buriti oil, to give sports drink beverage a bright reddish-looking color.

\section{INTRODUCTION}

Color is an important characteristic for food products, since it influences people's preference and choice [1]. For example, how would you feel if you 


\section{DYE}

A substance used to change the color of something.

\section{EMULSIFICATION}

A process that enables water and oil to mix with each other.

\section{EMULSION}

A mixture of two or more liquids that are normally unmixable.

\section{NANOEMULSION}

Emulsion with particles that are very tiny in size. bought a tangerine-flavored sports drink and it was green? It would be a bit weird, wouldn't it?

Several food products are naturally colorless and in other food products, the original color is lost due to industrial processing. For that reason, dyes are added to food to give color or to recreate the lost color, to make the foods attractive to us as consumers. Dyes can be artificial or natural. Some of the most common natural food dyes are carotenoids (yellow, orange, and red), chlorophyll (green), anthocyanins (red, blue), flavonoids and turmeric (yellow), and red paprika powder (red) [1]. The most used artificial dyes include sunset yellow and tartrazine (yellow), allura red and erythrosine B (red), and brilliant blue. For a long time, the use of artificial dyes has been controversial, and many dyes have even been banned because of their negative effects on laboratory animals and for their role in causing hyperactivity, allergies, and other negative side effects in children [2].

Since more and more people are becoming interested in eating healthy food, a large amount of research has been conducted to develop food products associated with good health [3]. This article describes research investigating the possibility of using a very nutritious reddish oil from the Amazon region, called buriti (Mauritia flexuosa L.) oil, as a natural dye for a tangerine-flavored sports drink. But, wait a minute, how can we add oil to a drink? If you have ever tried to add oil to water, you might have noticed that the two simply do not mix. But do not worry: this is possible through a process called emulsification.

\section{WHAT IS EMULSIFICATION AND AN EMULSION?}

Have you ever tried to add some drops of oil into a glass containing water? If you have, you probably realized that the water and the oil do not mix with each other. The same happens when you try to wash your oily hands with just water-your hands will remain very oily. Let us say that this happens because water and oil are enemies and they want to stay as far from each other as possible. However, making enemies is not a good thing, so we are going to explain a technique, called emulsification, which can make water and oil become good friends. When water and oil become friends, the mixture is called an emulsion.

Emulsions are classified according to many factors but most importantly according to (i) type of emulsion: water-in-oil and oil-in-water (Figure 1) and (ii) the size of their particles. When the particles are very tiny, they are called nanoemulsion (particle size: $10-100 \mathrm{~nm}$ ) [4]. Just so that you have an idea of how small the particles in a nanoemulsion are: imagine a $1-\mathrm{cm}$ long ant and a 1-nm long emulsion particle. Ten million of these particles together would have the same length as the ant. Compared with emulsions that have large particle sizes, nanoemulsions have many advantages when it comes to being used in food and beverage products. One of the advantages is that nanoemulsions are 


\section{FIGURE 1}

Example of two kinds of emulsions. A water-in-oil emulsion is when particles of water are dispersed in oil, and an oil-in-water emulsion is when particles of oil are dispersed in water.

\section{FIGURE 2}

Example of a stable and unstable water-in-oil emulsion. In a stable emulsion, there is no separation of the water and oil phase. In an unstable emulsion, there is a separation of the water and oil phase.
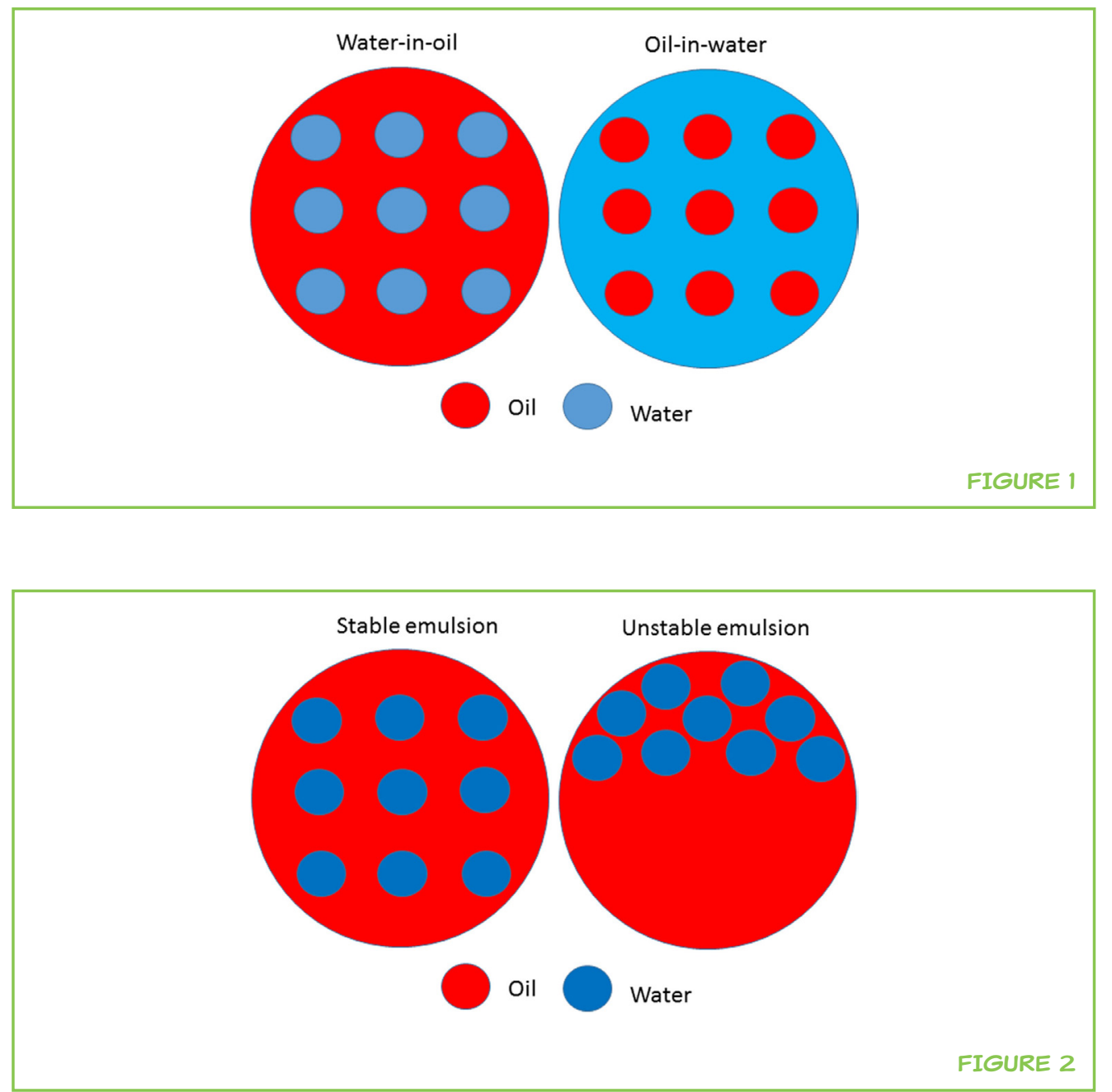

more stable (Figure 2). That means it is less likely that the oil and water would separate again after some time [4].

\section{HOW CAN EMULSIONS BE PRODUCED?}

Before explaining how emulsions can be made, we have to understand what molecules of water and oil look like. We can say that water and oil do not mix with each other because they do not like to be around substances that do not look like them, and also that do not like the same things as they do. Water molecules are "water-loving" that means they love water and fear oil and oil molecules are "oil-loving" that means they fear water and love oil. Water molecules only mix easily with other "water-looking/loving" molecules, and oil molecules only mix with "oil looking/loving" molecules. So, that means when you mix oil and water, water stays with water and oil goes away from water. There is also another reason why water and oil are enemies: they have different densities. Density is how compact a substance is. In mathematical terms, density is the mass of an object or substance divided by its volume (how much space it takes up). The density of oil is around $0.92 \mathrm{~kg} / \mathrm{l}$ and the density of water is around $1 \mathrm{~kg} / \mathrm{l}$. 


\section{FIGURE 3}

The emulsification process. On the left side we can see water, oil, and emulsifier altogether. At this point, it is not yet an emulsion as there is no source of energy applied. On the right side (after energy is applied), we can see that a stable water-inoil emulsion is formed.

\section{EMULSIFIER}

A substance used as the "bridge" between oil and water in an emulsion.

FOOD-GRADE

A substance that is safe to be eaten by humans.

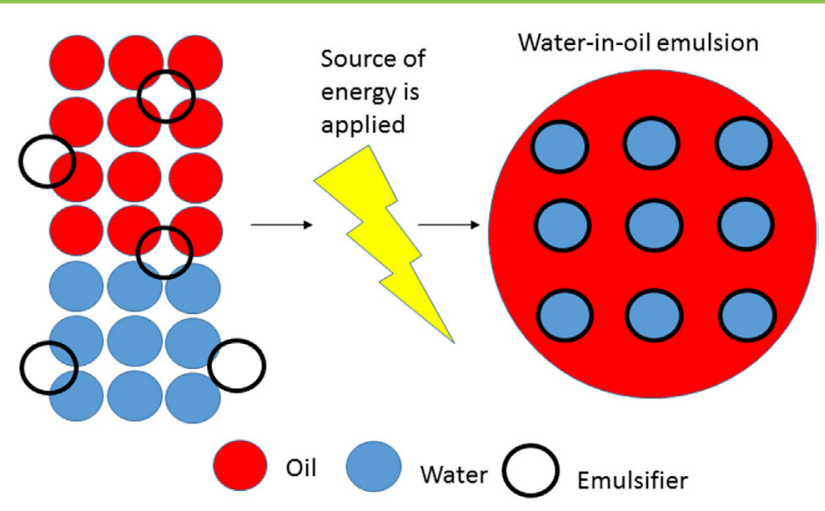

FIGURE 3

Now, let us go back to the example of washing our oily hands without soap. Hands remain oily without soap, don't they? Have you ever wondered why? It is because soap molecules look like water on one end and like oil on the other end, so they are attracted to both water and oil. Soaps work as emulsifiers. So let us think of the soap as being a bridge that connects water with oil and allows them to be friends. When you add the soap, one side of a soap molecule attaches to a water molecule and the other side attaches to an oil molecule. The soap then creates the bridge that connects the water with the droplets of oil spread through it.

However, if you just put water, oil, and soap together in a glass or if you just put soap to your hands, nothing will happen, you will not yet have an emulsion (or clean hands). To form an emulsion, you need to add some source of energy. In the case of your hands, you need to rub them against each other. In the case of a glass containing water, oil, and soap, you could add energy by shaking the mixture, and you will then form an emulsion that is formed through a process called emulsification (Figure 3). You can even try this at home.

So now, let us go back to the question of how we can produce emulsions. There are many methods to produce emulsions and nanoemulsions, and these emulsions can include various ingredients and sources of energy. Some of the methods need a lot of energy and for that reason they are called high-energy methods, and some do not need as much energy and are called low-energy methods. The sources of energy can be either stirring or shaking. Many ingredients can be added to an emulsion, but only three of them are essential: a water phase, an oil phase, and an emulsifier.

\section{HOW CAN EMULSIONS BE USED AS A NATURAL DYE?}

We just explained how to make an emulsion, but wait a minute-you cannot really eat soap, can you? So, in order to use an emulsifier to produce emulsions, we will need an emulsifier that can safely be added to food. There are many emulsifiers on the market that are food-grade and can be used in the food we eat. 
Here is how we used an emulsion as a natural dye. For the oil phase, we chose a very nutritious reddish-colored oil, called buriti (M. flexuosa $L$.) oil. Buriti is a palm tree commonly found in the Amazon region. The reddish color comes from the high amount of natural colorant that the oil possesses, which is from the carotenoids present in it. Buriti oil is also rich in a substance called tocopherols, which can form vitamin $\mathrm{A}$, and oleic acid, which is believed to reduce cholesterol levels [5]. As an emulsifier, we used a substance called polysorbate80, which is food-grade and is commonly used to produce ice cream. For the water phase, we used water. As an "extra" ingredient, we added a little bit of table salt. Salt was added to nanoemulsions to reduce the temperature needed during the emulsification process. By the way, did you know that sports drinks are full of minerals? These minerals include sodium $(\mathrm{Na})$, and guess what? Sodium is one of the main components in table salt $(\mathrm{NaCl})$. Since our nanoemulsion already contained salt, there was no need to add more salt to the sports drink formulation. We produced a nanoemulsion with these ingredients by a lowenergy method. After the nanoemulsion was done, we added some of it into sports drink as a natural dye. In our sports drink formulation, it was possible to replace $25 \%$ of the artificial dye by natural dye. In order to be able to substitute a higher percentage further work needs to be done in the sports drink formulation to improve the color, aroma, and flavor of the drink.

The work did not end there. We then did a sensory evaluation test, in which 100 people tried out the drink and evaluated it in terms of color, aroma, and flavor. They were asked to give grades from 1 to 9 , in which 1 meant they extremely disliked the drink and 9 meant that they extremely liked the drink (Figure 4). We found that the average grade given by 100 people in terms of color, aroma, and flavor were $6.2,4.3$, and 3.3, respectively. These results indicate that it was possible to substitute part of the artificial dye by natural dye while still maintaining an attractive color. It also shows that the nanoemulsion altered a bit the aroma and the flavor of the sports drink

FIGURE 4

A sensory evaluation test was performed on the sports drink. People who tried the drink rated it on color, aroma, and flavor. The closer to 9, the more people liked it. These results represent the average score for the sensory evaluation of 100 people. You can see that color was rated with the highest scores followed by aroma and flavor. That means that the most liked thing in the sports drink was its color.

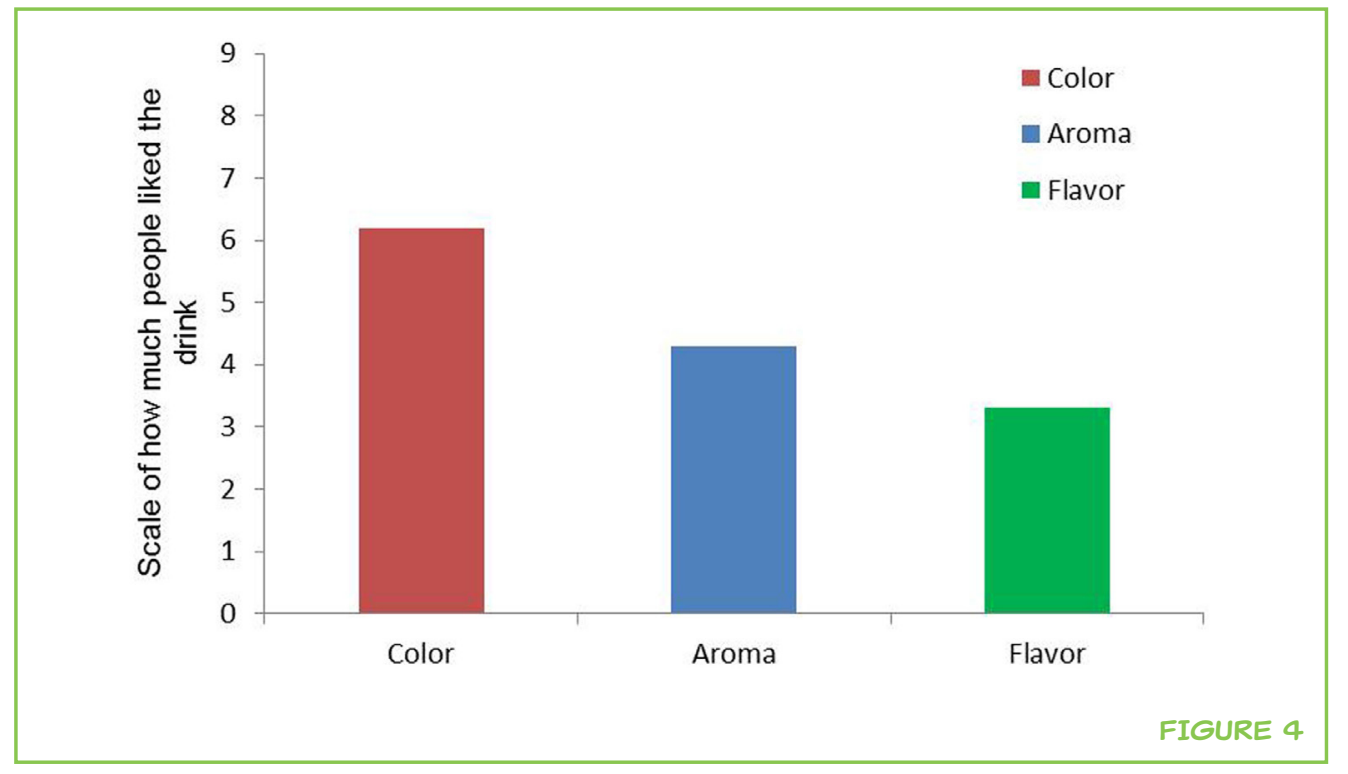


as they received lower grades. From these results we can also see that the addition of natural buriti oil nanoemulsion to the sports drinks affected more the flavor than the aroma of the drink. We think that the flavor and the aroma of the emulsifier we used (polysorbate80) might be the reason for the lower aroma and flavor scores. Still, if modifications (for example, use of a different emulsifier) on the nanoemulsion formulation would be made these differences can be reduced.

\section{CONCLUSION}

We hope that our research will inspire new investigations into how we can produce different kinds of natural dyes by the process of emulsification. Many different types of natural emulsion dyes could be produced and tested. For example, we can use the spice turmeric powder to produce a yellow natural dye and use it for pineapple ice cream coloring [6], or use paprika to produce a red natural dye and maybe use it to color strawberry yogurt. You might be wondering if adding turmeric powder or paprika to food will change the flavor and smell of the food, right? Well, apparently not so much. There has already been a study evaluating the sensory acceptance of turmeric powder in ice cream [7]. The results indicated that some improvement in the recipe was still needed in order to replace all of the artificial yellow dye with a turmeric powder nanoemulsion, but partial replacement was well accepted. Regarding the paprika, we still need to try it out and see! Hopefully, with future research, we will be able to replace, fully or at least partially, all controversial, artificial food dyes with natural dyes made from emulsions.

\section{ORIGINAL SOURCE ARTICLE}

Bovi, G. G., Petrus, R. R., and Pinho, S. C. 2017. Feasibility of incorporating buriti (Mauritia flexuosa L.) oil nanoemulsions in isotonic sports drink. Int. J. Food Sci. Technol. 52(10) 2201-9. doi:10.1111/ijfs.13499

\section{REFERENCES}

1. Pathare, P. B., Opara, U. L., and Al-Said, F. A.-J. 2013. Colour measurement and analysis in fresh and processed foods: a review. Food Bioproc. Tech. 6(1):36-60. doi:10.1007/s11947-012-0867-9

2. Kobylewski, S., and Jacobson, M. F. 2010. Food Dyes: A Rainbow of Risks. Washington, DC: Center for Science in the Public Interest.

3. Huang, Q., Yu, H., and Ru, Q. 2010. Bioavailability and delivery of nutraceuticals using nanotechnology. J. Food Sci. 75(1):R50-7. doi:10.1111/j.1750-3841.2009.01457.x 
4. McClements, D. J., and Rao, J. 2011. Food-grade nanoemulsions: formulation, fabrication, properties, performance, biological fate, and potential toxicity. Crit. Rev. Food Sci. Nutr. 51(4):285-330. doi:10.1080/10408398.2011.559558

5. Albuquerque, M. L. S., Guedes, I., Alcantara, P. Jr., Moreira, S. G. C., Barbosa Neto, N. M., Correa, D. S., et al. 2005. Characterization of buriti (Mauritia flexuosa L.) oil by absorption and emission spectroscopies. J. Braz. Chem. Soc. 16:1113-7. doi:10.1590/S0103-50532005000700004

6. Borrin, T. R., Georges, E. L., Moraes, I. C. F., and Pinho, S. C. 2016. Curcuminloaded nanoemulsions produced by the emulsion inversion point (EIP) method: an evaluation of process parameters and physico-chemical stability. J. Food Eng. 169:1-9. doi:10.1016/j.jfoodeng.2015.08.012

7. Borrin, T. R., Georges, E. L., Brito-Oliveira, T. C., Moraes, I. C. F., and Pinho, S. C. 2018. Technological and sensory evaluation of pineapple ice creams incorporated with curcumin-loaded nanoemulsions obtained by the emulsion inversion point method. Int. J. Dairy Technol. 71:491-500. doi:10.1111/14710307.12451

SUBMITTED: 17 May 2018; ACCEPTED: 24 August 2018;

PUBLISHED ONLINE: 10 September 2018.

EDITED BY: Kelly Westlake, University of Maryland, United States

CITATION: Bovi GG and Pinho SC (2018) Emulsions Can Replace Artificial Dyes in Beverages. Front. Young Minds 6:48. doi:10.3389/frym.2018.00048

CONFLICT OF INTEREST STATEMENT: The authors declare that the research was conducted in the absence of any commercial or financial relationships that could be construed as a potential conflict of interest.

COPYRIGHT @ 2018 Bovi and Pinho. This is an open-access article distributed under the terms of the Creative Commons Attribution License (CC BY). The use, distribution or reproduction in other forums is permitted, provided the original author(s) and the copyright owner(s) are credited and that the original publication in this journal is cited, in accordance with accepted academic practice. No use, distribution or reproduction is permitted which does not comply with these terms.

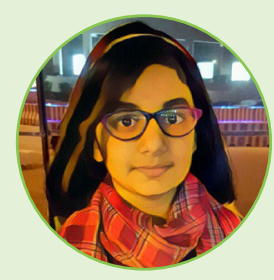

\section{REVIEWED BY}

\section{ALAA, AGE: 10}

I am Alaa, an $A^{*}$ student whose favorite subject is science. I LOVE learning. I am an avid reader and a chocoholic (blame my mummy!). When I grow up, I want to be a pilot (think I still have time to decide on that). I love traveling and have travelled to many fascinating places like Amsterdam, AbuDhabi, Frankfurt, London, Canada, Turkey, and plan to visit many more in future. I enjoy watching cartoons, educational videos, drawing, and coloring. I love playing badminton. 


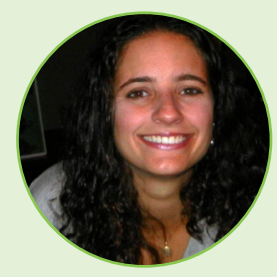

\section{AUTHORS}

\section{GRAZIELE G. BOVI}

Graziele Grossi Bovi studied Food Engineering at the University of São Paulo in Brazil. For her master's degree, she worked on the production, characterization, and stability evaluation of nanoemulsions using buriti oil for use in beverages, aiming to replace artificial color, especially sunset yellow, with a natural dye. Currently in her PhD studies, she works to improve the packaging of fresh fruits and vegetables. Outside her research, she enjoys jogging, traveling, cooking, reading, and watching TV series. *gbovi@atb-potsdam.de

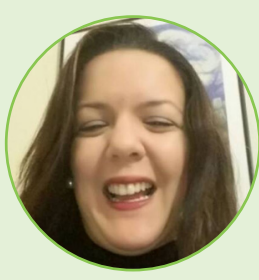

\section{SAMANTHA C. PINHO}

Samantha C. Pinho is a Brazilian Chemical Engineer, with a MSc. in Chemical Engineering and Ph.D. in Civil Engineering. She is an associate professor at the Department of Food Engineering of University of São Paulo (USP), Brazil, where she has been teaching and doing research since 2005. The main aim of her research group, which is the Laboratory of Encapsulation and Functional Foods, is to develop foods containing different types of antioxidants and vitamins, and to evaluate their digestion. 